
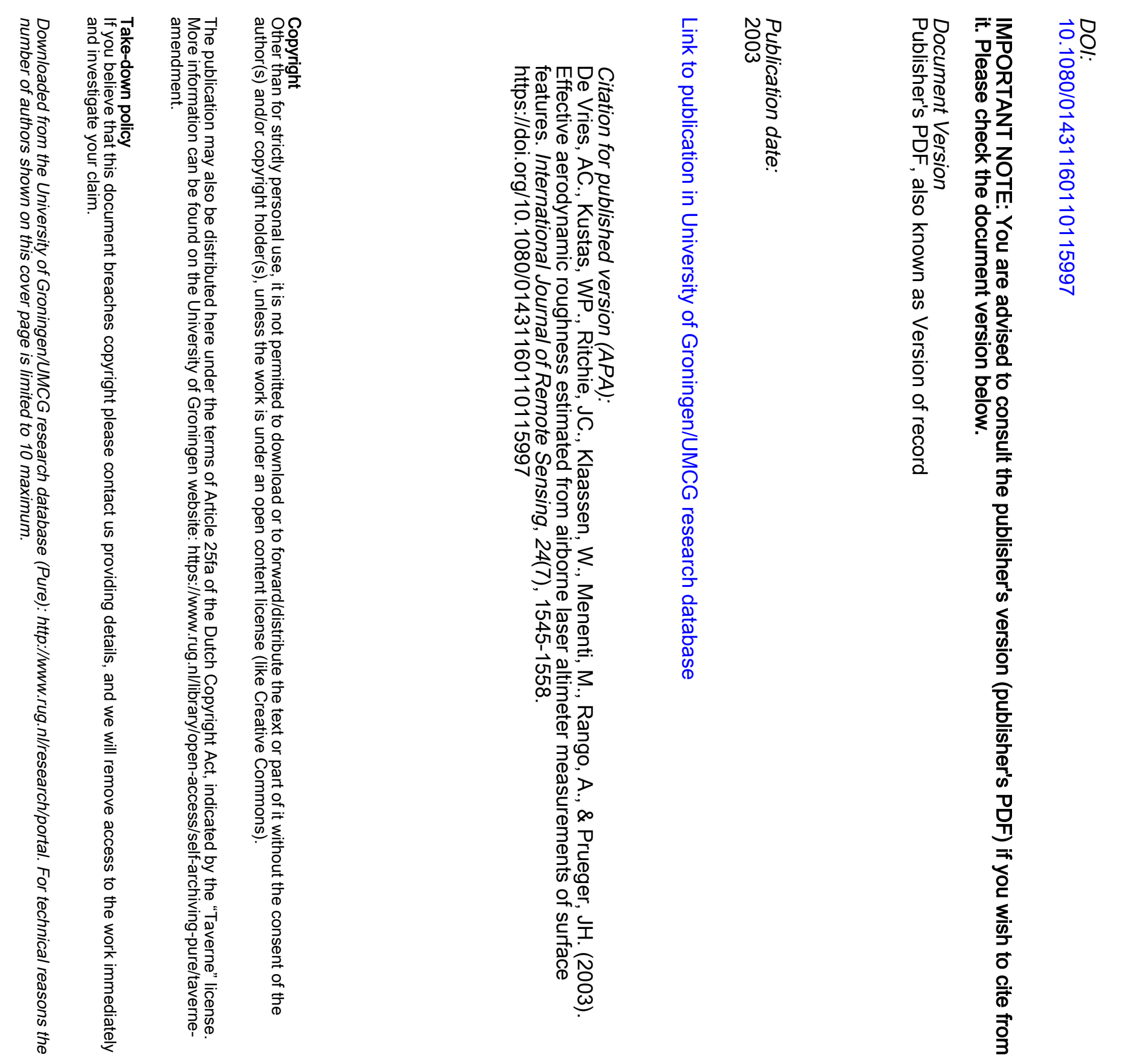

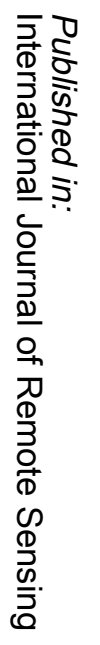

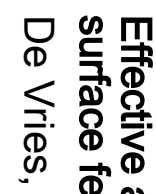

邑邑

조용

क

$\sum$ 궁

ํํ 응

끌 可

하 \&

ก 急

즈

D)

$\stackrel{1}{3}$

$\sum \quad$

잉

D

ᄅ. क

$3 \quad$

分 害

응

ㄱ.

굴

(1)

立
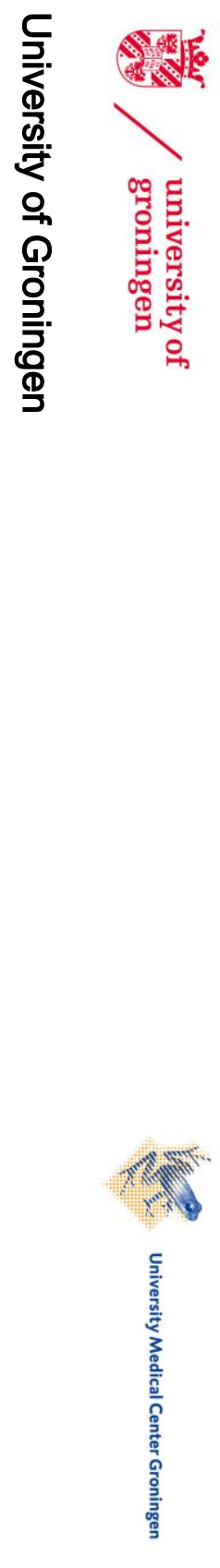


\title{
Effective aerodynamic roughness estimated from airborne laser altimeter measurements of surface features
}

\author{
A. C. DE VRIES ${ }^{1}$, W. P. KUSTAS 2 , J. C. RITCHIE ${ }^{2}$, \\ W. KLAASSEN ${ }^{3}$, M. MENENTI ${ }^{4}$, A. RANGO ${ }^{5}$ and J. H. PRUEGER 6 \\ ${ }^{1}$ Department of Water Resources and Planning, Royal Haskoning, Rotterdam, \\ The Netherlands \\ ${ }^{2}$ Hydrology and Remote Sensing Laboratory, Beltsville Agricultural Research \\ Center, Agricultural Research Service, US Department of Agriculture, Beltsville, \\ Maryland 20705, USA; e-mail: jritchie@hydrolab.arsusda.gov \\ ${ }^{3}$ Department of Marine Biology, University of Groningen, Groningen, \\ The Netherlands \\ ${ }^{4}$ Universite Louis Pasteur, Strasbourg, France \\ ${ }^{5}$ Jornada Experimental Range, Agricultural Research Service, US Department \\ of Agriculture, Las Cruces, NH 88003, USA \\ ${ }^{6}$ National Soil Tilth Laboratory, Agricultural Research Service, US Department \\ of Agriculture, Ames, Iowa 50011, USA
}

(Received 4 December 1997; in final form 22 October 2001)

\begin{abstract}
Aerodynamic roughness length $\left(z_{0}\right)$ and displacement height $\left(d_{0}\right)$ are important surface parameters for estimating surface fluxes in numerical models. These parameters are generally determined from wind flow characteristics using logarithmic wind profiles measured at a meteorological tower or by balloon release. It would be an advantage to use measurements of land surface characteristics instead of wind flow characteristics to estimate the $z_{0}$ and $d_{0}$ for large areas. Important land surface characteristics are the size and distribution of roughness elements (obstacles). This research evaluates the use of high resolution laser altimeter data to obtain these land surface characteristics. Data were collected at the US Department of Agriculture, Agricultural Research Service (USDA-ARS), Jornada Experimental Range in southern New Mexico, USA over a coppice dune dominated area. These dunes are covered by honey mesquite (Prosopis glandulosa Torr.) with flat and mostly bare interdunal areas. For this analysis, three $450 \mathrm{~m}$ laser transects with a $2 \mathrm{~cm}$ measurement interval were used. The distribution and size of dunes were calculated from these laser transects and used to compute $z_{0}$. Analysis gave an average $z_{0}=4.3 \mathrm{~cm}$ and $d_{0}=70 \mathrm{~cm}$ for the three laser transects, which compares to $z_{0}=7 \pm 4 \mathrm{~cm}$ and $d_{0}=98 \pm 48 \mathrm{~cm}$ calculated from wind profile data measured at a $10 \mathrm{~m}$ tower near the laser transects. These results show that the estimation of $z_{0}$ and $d_{0}$ for a complex terrain is possible using simple land surface features computed from high resolution laser altimeter data.
\end{abstract}

\section{Introduction}

For momentum transfer modelling, the nature of the land surface can be characterized by the aerodynamic roughness length $\left(z_{0}\right)$ and the displacement height $\left(d_{0}\right)$. The roughness length $z_{0}$ is defined by the logarithmic wind profile which is valid in the lower part of a neutrally stratified boundary layer over homogeneous terrain. In

International Journal of Remote Sensing

ISSN 0143-1161 print/ISSN 1366-5901 online (C) 2003 Taylor \& Francis Ltd

http://www.tandf.co.uk/journals

DOI: $10.1080 / 01431160110115997$ 
case of a vegetative canopy, the wind profile will only behave logarithmically above the canopy layer. The height at which the wind begins to behave logarithmically is known as the displacement height $d_{0}$. In complex land surfaces, disturbances of the boundary layer by roughness elements (obstacles) often does not allow a local equilibrium to occur. In such cases an effective aerodynamic roughness accounting for the heterogeneities of the land surface needs to be estimated. The effective aerodynamic roughness is a function of the different roughness elements at different scales and distributions of roughness elements, i.e. the heterogeneity of the land surface. To compute the effective aerodynamic roughness from the surface geometry over a complex land surface, several algorithms (Raupach et al. 1980, Mason 1985, Kustas and Brutsaert 1986, Grant and Mason 1990) have been proposed. To compute the displacement height from surface features, Kutzbach (1961) put forward an algorithm. To apply these algorithms, extensive measurements of the size and distribution of roughness elements are necessary.

Hiyama et al. (1996) calculated $z_{0}$ for a complex terrain using the algorithms of Grant and Mason (1990) and Raupach et al. (1980) and calculated $d_{0}$ using the algorithm of Kutzbach (1961). They derived surface features from aerial photographs and from field data of obstacle heights. Wind profile measurements were used to calibrate the models and derive the drag coefficient. The need for extensive field data makes this approach less useful for application to large areas. Menenti and Ritchie (1994) estimated the effective aerodynamic roughness for a watershed in Arizona, USA using airborne laser measurements of surface roughness. They estimated roughness due to shear stress from the ratio of the standard deviation of vegetation height to average vegetation height. They estimated effective aerodynamic roughness using the method of Arya (1975) which includes parameters that cannot be determined easily from laser altimeter data and which had to be approximated. These parameters are the base width of the region with separate airflow behind obstacles and the restoration length of the logarithmic wind profile after obstacles. Menenti and Ritchie (1994) estimated an effective aerodynamic roughness length which includes the effect of topography from the model of Taylor et al. (1989). The current study is an extension of Menenti and Ritchie's (1994) research on the use of laser altimeter measurements of land surface roughness to derive the effective aerodynamic roughness length in complex terrain. Our study evaluates the use of high resolution laser altimeter data for the estimation of the effective aerodynamic roughness in a coppice dune area in New Mexico, USA.

\section{Data}

2.1. Study area

Laser altimetry measurements were made during the JORNEX campaign (Havstad et al. 2000) in May 1995 at the USDA-ARS Jornada Experimental Range $\left(783 \mathrm{~km}^{2}\right)$ which is in the Chihuahuan desert ecosystem in the Mexican Highland section of the Basin and Range Province of southern New Mexico, $37 \mathrm{~km}$ north of Las Cruces, New Mexico, USA. Annual average precipitation and temperature are $241 \mathrm{~mm}$ and $15^{\circ} \mathrm{C}$, respectively. Winds are predominantly from the south-west. The flora and fauna are typical of a subtropical ecosystem in the hot desert biome. The study area includes part of the north-south trending mountain ranges and the broad valley of the Rio Grande river. The east side of the site is dominanted by the Organ and San Andres Mountains with elevation up to $2750 \mathrm{~m}$ while the western side is dominated by the Dona Ana and Robledo Mountains with elevation up to $1830 \mathrm{~m}$. 
The valley of the Rio Grande has an average elevation of $1200 \mathrm{~m}$. Many small playas and drainage ways with clayey and silty textures mark the undulating basin.

The current study concentrates on the part of the basin characterized by large coppice dunes covered with honey mesquite (Prosopis glandulosa Torr.) with flat and mostly bare interdunal areas and an area of smaller coppice dunes with interdunal areas partially covered with grasses and forbs. Due to overgrazing and periodic drought, honey mesquite dominates vast areas formerly covered by grass (Grover and Musick 1990). The bare soil in the interdunal areas permits wind erosion and the development of coppice dunes. The height of the coppice dunes ranges from 1 to $3 \mathrm{~m}$ with a diameter of 1 to $15 \mathrm{~m}$ (Gibbens et al. 1983).

A 100-m engineering ground survey cross section through the coppice dunes yielded estimates of dune topography and mesquite vegetation height and density of the dunes (Havstad et al. 2000). The dunes in this $100 \mathrm{~m}$ transect, which was the same as one of the laser transects, ranged from $0.32-2.20 \mathrm{~m}$ high with an average dune height of $0.84 \mathrm{~m}$. Mesquite is clumped on the tops of the dunes, and when the vegetation height is added to the dune height, the height range went from $1.13-3.51 \mathrm{~m}$ with an average total dune plus mesquite height of $1.80 \mathrm{~m}$.

\subsection{Laser measurement}

Three airborne laser transects made in May 1995 of $450 \mathrm{~m}$ each were used for this study. Two transects were in the south to north direction and one was in the west to east direction (figures 1 and 2). One of the south to north transects $\left(N S_{S D}\right)$ covered an area of smaller dunes with some interdunal vegetation. The other two transects $\left(N S_{L D}\right.$ and $\left.E W_{L D}\right)$ covered areas of larger dunes with bare interdunal areas. All transects were within $200 \mathrm{~m}$ of a $10 \mathrm{~m}$ meteorological tower (see \$2.3). The laser altimeter is a pulsed gallium-arsenide diode laser, transmitting and receiving 4000 pulses per second at a wavelength of $904 \mathrm{~nm}$. At nominal aircraft speed, the altimeter makes measurements at $2 \mathrm{~cm}$ intervals with a vertical resolution of $5 \mathrm{~cm}$ for each measurement (Ritchie 1995).

\subsection{Wind profile measurements}

From May 1996 to February 1997 wind profile data were collected from a $10 \mathrm{~m}$ meteorological tower. The tower was instrumented with sensors to measure air

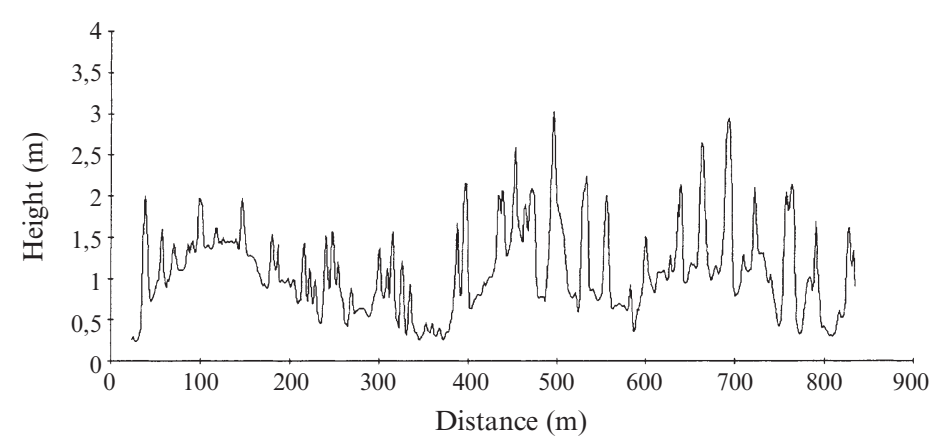

Figure 1. A topographic profile measured with a laser altimeter on the north-south transect of a coppice dune area with small dunes from 0 to $400 \mathrm{~m}$ and an area of larger dunes from 400 to $800 \mathrm{~m}$. Laser data were detrended and block averaged using ten measurements. 


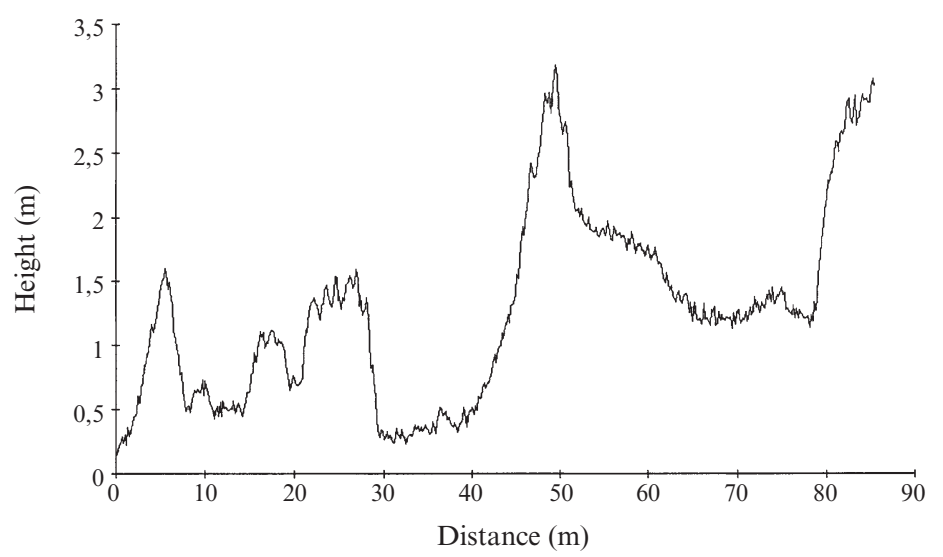

Figure 2. Detail of a topographic profile of a coppice dune area measured with a laser altimeter. Laser data were detrended and block averaged using ten measurements to show the fine scale structure.

temperature, water vapour pressure and wind speed at heights $3,4,5,6,8$ and $10 \mathrm{~m}$ above the ground surface.

Air temperature and vapour pressure were measured using Vaisala temperature and relative humidity probes (model HMP 35C). (Trade names are included for the benefit of the reader and do not imply an endorsement of or a preference for the product listed by the University of Groningen, US Department of Agriculture, or DLO Winand Staring Centre.) Specifications of the relative humidity accuracy are $\pm 2 \%$ between $0-90 \%$ and $\pm 3 \%$ between $90-100 \%$. Air temperature accuracy is $\pm 0.4^{\circ} \mathrm{C}$ over the range of -24 to $48^{\circ} \mathrm{C}$. The HMP $35 \mathrm{C}$ was placed inside an aspiration shield fitted with an Aromat AIF-60 DC powered fan. Ambient air was advected past the HMP 35C sensor elements at a constant flow rate of $3.0 \mathrm{~m} \mathrm{~s}^{-1}$. The intake barrels of the aspiration shields were oriented to the north to minimize thermal loading at the mouth of the barrel which can induce temperature bias of the measurements.

Wind speeds were measured with R. M. Young 3-cup photochopper anemometers with a threshold sensitivity of $0.3 \mathrm{~m} \mathrm{~s}^{-1}$. The transducer output produced a voltage pulse with a frequency proportional to wind speed.

Bias in the sensors was estimated by positioning them at $2 \mathrm{~m}$ above a grass surface for several days before placing them on the tower. The co-location data were used to fit least squares regression equations among individual sensors and the average given by the six sensors. For air temperature, standard errors of individual sensors from the average of the six were typically on the order of $0.1^{\circ} \mathrm{C}$ while for wind speed, standard errors of individual sensors from the average of the six were typically on the order of $0.01 \mathrm{~m} \mathrm{~s}^{-1}$.

\subsection{Determination of aerodynamic roughness and displacement height from wind profile data}

Preliminary estimates of both $z_{0}$ and displacement heights $\left(d_{0}\right)$ were computed from the wind profiles using data under near-neutral conditions estimated using the 
gradient Richardson number $\left(R_{i}\right)$,

$$
R_{i}=\frac{g}{T_{a}} \frac{\partial \theta}{\partial z} /\left(\frac{\partial u}{\partial z}\right)^{2}
$$

where $T_{a}$ is air temperature, $g$ is acceleration of gravity, $\theta$ is potential temperature, $z$ is height above ground and $u$ is wind speed. If temperature gradients $\left(\partial T_{a} / \partial z\right)$ are measured close to the surface, they can replace $\partial \theta / \partial z$ with little error in estimating $R_{i}$. When $R_{i} \rightarrow 0$, the wind profile is generally accepted to be logarithmic (Brutsaert 1982) as shown in the following equation:

$$
u=\frac{u_{*}}{k} \ln \frac{z-d_{0}}{z_{0}}
$$

where $u_{*}$ is the friction velocity and $k$ is the von Karman's constant. Probably the most widely used approach for estimating $z_{0}$ and $d_{0}$ is to have several levels of wind measurements to mathematically solve for $z_{0}$ and $d_{0}$ using equation (2) by minimization of square errors (Robinson 1962, Stearns 1970). Covey (1963) developed a procedure to solve for $d_{0}$ numerically using an expression which is essentially a linear function of $d_{0}$. The approach is described in more detail in Kustas et al. (1989) and here used to estimate $z_{0}$ and $d_{0}$ from the wind profile data.

The upwind fetch or source area affecting the wind speed measurements varies with surface roughness, wind speed, atmospheric stability and other turbulence characteristics (Schmid 1994). With measurement heights from 3 to $10 \mathrm{~m}$, surface features upwind nominally from $\sim 100 \mathrm{~m}$ to $1000 \mathrm{~m}$ would be most influential on the observations (Schuepp et al. 1990).

\section{Estimation of effective aerodynamic roughness and displacement height from surface features}

\subsection{Theory}

Airflow over hills or dunes is influenced by their shape and size (figure 3). For two-dimensional dunes, wind will accelerate at the upwind side, reach a maximum velocity at the dune crest and then decelerate behind the dune. Depending on the steepness of the downwind slope, a separation bubble can form at the foot of the dune where the wind direction will be opposite the general flow. Behind dunes, a wake region will develop with a decreased wind velocity extending for several dune heights downwind. In three-dimensional dunes, a region of lateral flow divergence

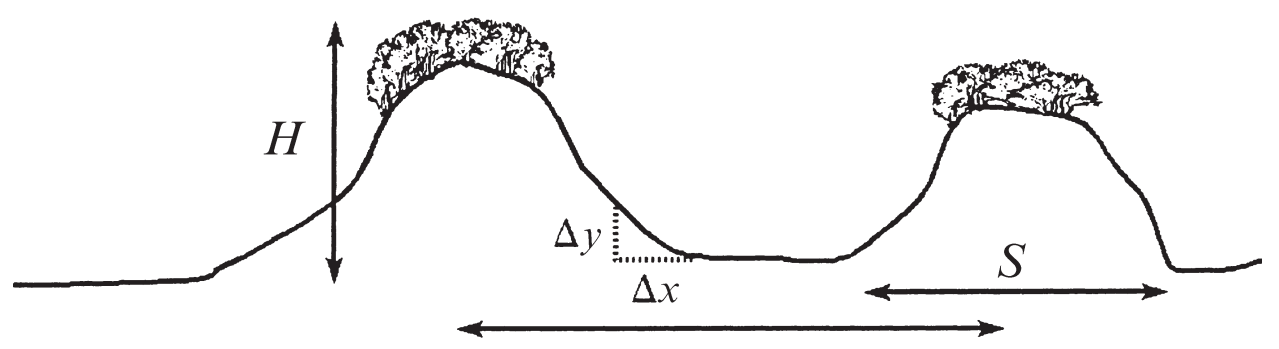

$L$

Figure 3. Schematic of the coppice dunes showing the different model parameters of the surface. 
will develop as the flow streamline divides to pass around the dune. The divergence will decrease while moving up the crest and will disappear at the crest of the dune (Kaimal and Finnigan 1994).

Mason (1985) reviewed the effects of hills on aerodynamic roughness and found that the effect depends on their shape, size, and spatial distribution. For flow over an area with low density dunes or obstacles, aerodynamic roughness varies in proportion to the height of the obstacle. For dense arrays of obstacles, occupying at least $10 \%$ of the surface area and with steep slopes $>45 \%, z_{0}$ may reach a maximum value up to $0.1 \times H$, where $H$ is the obstacle height. This estimation should be used as the upper limit for $z_{0}$. For areas with dense arrays of roughness elements with moderate slopes $<45 \%, z_{0}$ is less than $0.1 \times H$ and depends on shape, size, and distribution of obstacles. For surfaces where $10-50 \%$ of the ground area is covered by obstacles (depending on the shape of the dunes), $z_{0}$ will increase with increasing obstacle density to a maximum. Obstacle density for which the maximum $z_{0}$ occurs depends on the geometry of the roughness elements. At higher obstacle densities, obstacles lie in each other's wake, causing a decrease in $z_{0}$.

For obstacles with moderate slopes, different solutions at different scales of the land surface can be applied to infer the appropriate roughness lengths from simple terrain characteristics. In bluff-rough surfaces, where sparse obstacles like trees only influence the roughness, Lettau (1969) proposed the following equation:

$$
z_{0}=C H \lambda
$$

where $H$ is the average obstacle height and $\lambda$ is the density of the roughness elements. $\lambda$ can be estimated by $A / S$ where $A$ is the average silhouette area of the roughness elements in a horizontal area $(S)$. $C$ is assumed to be a constant for which Lettau (1969) used 0.5 for $A / S<0.1$. For two-dimensional obstacles, the calculation of $A / S$ can be simplified to $A / S=H / L$, where $L$ in the wavelength (distance between obstacles). Wooding et al. (1973) proposed $C$ as a shape factor and based on wind tunnel data for $k=0.35$, where $k$ is the von Karman's constant, proposed that:

$$
C=2.05\left(\frac{H}{S}\right)^{0.4}
$$

Taking the more classical value $k=0.4$, Kustas and Brutsaert (1986) suggested the following equation for the aerodynamic roughness in complex terrain:

$$
\frac{z_{0}}{H}=\lambda\left(\frac{H}{S}\right)^{0.4}
$$

where $S$ is the average horizontal dimension of the roughness element. The shape of the obstacles is not taken into account (except through $\lambda$ ).

Raupach et al. (1980) gave a summary of wind tunnel data on wind flow past regular arrays of obstacles. For a range of bluff bodies they found $z_{0} \sim H \times A / S$ for $A / S$ smaller than 0.1 and a maximum value of $z_{0} \sim 0.1 \times H$ when $A / S$ is approximately 0.2 . For $A / S$ greater than $0.2, z_{0} / H$ decreases with increasing $A / S$.

The above equations account for the form drag caused by large scale roughness elements but neglect the contribution of shear stress caused by small scale roughness elements like vegetation and smaller scale irregularities. Total drag $\left(F_{t}\right)$ consists of both form drag $\left(F_{f}\right)$ and shear stress $\left(F_{s}\right)$ :

$$
F_{t}=F_{f}+F_{s}
$$


Form drag $\left(F_{f}\right)$ is the drag from roughness elements per unit horizontal area and is due to larger obstacles, i.e. topography, dunes, trees, etc. Shear stress $\left(F_{s}\right)$ is due to the surface area and represents frictional stress due to small scale roughness elements. Grant and Mason (1990) suggested the following model for the concept of drag given by form drag and shear stress. For $F_{f}$, the expression is

$$
F_{f}=0.5 \rho C_{d} A u^{2}(H / 2)
$$

where $C_{d}$ is the drag coefficient, $\rho$ is air density, $A$ is the average silhouette area of the roughness elements and $u(H / 2)$ is the wind speed at $H / 2$. For bluff bodies $C_{d}$ varies between 0.2 for a sphere and 0.8 for rectangular bodies (Mason 1985) and depends on the slope of the obstacles. Hignett and Hopwood (1994) and Grant and Mason (1990) use a value of $C_{d}=0.3$ to calculate $z_{0}$ for an area with sinusoidal orography while Menenti and Ritchie (1994) use a value of $C_{d}=0.4$ to calculate $z_{0}$ for an area with shrubs. Hiyama et al. (1996) used a value of $C_{d}=0.5$ for a complex area with patches of various types of cover. For the current study a value of $C_{d}=$ 0.3 is used.

Using the local roughness related to grass, the shear stress contribution can be estimated by:

$$
F_{s}=\frac{k^{2}}{\ln ^{2}\left(H / 2 z_{01}\right)} \rho u^{2}(H / 2) S
$$

With local roughness $\left(z_{01}\right)$ being the shear stress of flat terrain and estimated as $1 \mathrm{~cm}$ in this research since the local roughness elements mainly consist of small patches of grass or forbs. Wieringa (1993) gives a maximum value of $6 \mathrm{~cm}$ for long grass. With only $10-20 \%$ of our study area covered by grass and up to $90 \%$ covered by bare soil, the local roughness was estimated as $1 \mathrm{~cm}$, ignoring the roughness contribution of the bare soil.

Total drag $F_{t}$ is related to the effective landscape roughness $z_{0}$ and can be expressed as:

$$
F_{t}=\frac{k^{2}}{\ln ^{2}\left(H / 2 z_{0}\right)} \rho u^{2}(H / 2) S
$$

From equation (4) it follows that:

$$
z_{0}=\frac{1}{2} H /\left\{\exp \left[k /\left\{\left(0.5 C_{d} \lambda+k^{2} / \ln ^{2} 2\left(H / 2 z_{01}\right)\right)^{0.5}\right\}\right]\right\}
$$

In this model shadowing effects of roughness elements are ignored. It is valid for obstacle slopes $\tan \theta>0.2$. For slopes $\tan \theta<0.1$, the influence of the obstacle drag on the roughness can be neglected while for slopes $0.1<\tan \theta<0.2$, Mason (1985) suggests that the roughness should be parameterized based on linear theory and not bluff body dynamics theory.

$$
\log \left(\frac{z_{0}}{z_{01}}\right)=\frac{1}{k^{2}} \log \left(1+63 \times 6.4 \tan \theta^{2}\right)
$$

In summary, for slopes $\tan \theta<0.1$, the form drag can be neglected and $z_{0}$ is estimated by the shear stress (equation (8)). For slopes $0.1<\tan \theta<0.2$, the roughness is parameterized by linear theory and $z_{0}$ is estimated by equation (11). For slopes $\tan \theta>0.2$, the roughness is due to both form drag and shear stress and $z_{0}$ is estimated by equation (7). 
The displacement height $d_{0}$ can be related to the density of the roughness obstacles for bluff-rough surfaces (Kutzbach 1961):

$$
d_{0}=d \lambda^{e} H
$$

where $d$ and $e$ are constants, which were approximated to be $d=1.09$ and $e=0.29$ over the range of approximately $0.09<\lambda<0.18$ (Raupach et al. 1980).

\subsection{Surface features}

The effective aerodynamic roughness of the laser altimeter measured landscape transects was calculated using equation (7) (Kustas and Brutsaert 1986), equation (8) (Grant and Mason 1990), and equation (9) (Mason 1985). To apply these equations, values for the obstacle density $(\lambda)$, the slope $(\theta)$, average obstacle height $(H)$, average obstacle width $(S)$, and average distance between obstacles landscape scale $(L)$ are calculated from the laser altimeter transect data.

For the current study, only the larger scale dunes $(H>50 \mathrm{~cm})$ are used for the calculation of obstacle drag. First, a block average of 10 laser measurements was applied to eliminate small scale variations in the laser data. This resulted in a horizontal resolution of $20 \mathrm{~cm}$. Secondly, a moving average was applied to eliminate random and system noise in the laser data. To determine the correct moving average, the obstacle density versus the number of measurements in a moving average is plotted. Obstacle density $(\lambda)$ was computed by integrating positive height changes divided by the distance using:

$$
\lambda=\frac{\sum \Delta y}{\sum \Delta x} \quad \text { for } \quad \Delta y>0
$$

where $\Delta y$ is the height difference for each $\Delta x$ in the section length. The curve has two components. A steep negative slope caused by instrument noise and a shallow negative slope caused by the surface geometry. A linear fit for those two components gave an intersection at a moving average of seven measurements for transects consisting of large dunes and a moving average of five for transects consisting of smaller dunes.

Roughness elements in the experimental area consist of dunes and vegetation. Sparse vegetation present in the interdunal area was excluded from the analysis. Vegetation on the dunes was included in the analysis as part of the dunes. So we implicitly assume that it is not important for the drag calculation whether $\Delta y / \Delta x$ is due to topography or to vegetation.

The width $(S)$ of the dunes was defined to begin at a positive height change of at least $2 \mathrm{~cm}$ between adjacent averaged measurements and to end at a negative height change of at least $2 \mathrm{~cm}$ between adjacent averaged measurements. The height of dunes should be at least $50 \mathrm{~cm}$. Average slope $(\tan \theta)$ of dunes was estimated by $H /(0.5 \times S)$ where $H$ is the peak to valley height and the $S$ is the horizontal scale over which height changes. We assume that larger scale undulations $(>1 \mathrm{~km})$ in topography do not contribute to the roughness elements (see equations (10) and (11)). Using these criteria, dune characteristics based on three laser transects were computed from the south to north laser transect $\left(N S_{L D}\right)$ and the west to east laser transect $\left(E W_{L D}\right)$ for the large dune area and the south to north laser transect $\left(N S_{S D}\right)$ for the smaller dune area (table 1 ). The spacing $(L)$ between the dunes was estimated as the average distance between the dune tops. 
Table 1. Summary of surface features of coppice dunes measured along three laser altimeter transects made at the USDA-ARS Jornada Experimental Range in New Mexico, USA.

\begin{tabular}{lcccc}
\hline & $\begin{array}{c}\text { Transect } \\
N S_{L D}\end{array}$ & $\begin{array}{c}\text { Transect } \\
E W_{L D}\end{array}$ & $\begin{array}{c}\text { Transect } \\
N S_{S D}\end{array}$ & Average \\
\hline Density $(\lambda)$ & 0.11 & 0.11 & 0.07 & 0.09 \\
Height $(H)(\mathrm{m})$ & 1.32 & 0.97 & 0.83 & 1.04 \\
Width $(S)(\mathrm{m})$ & 12.7 & 8.8 & 13.0 & 11.5 \\
Slope $(\tan \theta)$ & 0.21 & 0.22 & 0.13 & 0.19 \\
Spacing $(L)(\mathrm{m})$ & 38 & 31 & 25 & 31 \\
\hline
\end{tabular}

$N S_{L D}=$ North/South Large Dunes

$E W_{L D}=$ East/West Large Dunes.

$N S_{S D}=$ North/South Small Dunes.

\section{Results}

Wind profile data were used where the average $\left|R_{i}\right|$ for all six levels was typically less than 0.01 . These criteria resulted in more than 300 profiles, $70 \%$ of which gave a solution. Estimates of $z_{0}$ and $d_{0}$ from the wind profile data encompassing all wind directions were $7 \mathrm{~cm}( \pm 4 \mathrm{~cm})$ and $98 \mathrm{~cm}( \pm 48 \mathrm{~cm})$, respectively. Average values of $z_{0}$ and $d_{0}$ did change with wind direction. This can be seen in table 2 where average and standard deviations of $z_{0}$ and $d_{0}$ are given for winds from the four cardinal coordinates (i.e. north, south, east and west). However differences in the values of $z_{0}$ and $d_{0}$ with wind direction are not considered significant since the global values fall with one standard deviation of the means.

With the global values, this yields $z_{0} / H \approx 0.07$ and $d_{0} / H \approx 0.94$. A value of $d_{0} / H \sim 1$ has not been observed even for densely covered surfaces (Wieringa 1993) suggesting the roughness sublayer effects, which include location-dependent flow variations and wakes generated by local individual obstacles, may be affecting the wind profile measurements. However, preliminary analysis of the observed wind and temperature profiles by Kustas et al. (1998) under unstable conditions indicate a significant departure from the theoretical profiles defined by Monin-Obukhov similarity (Brutsaert 1982) existed for temperature only and not for wind. This effect on the temperature profile may be due to large spatial variations in surface temperature between dune and interdune areas which causes significant scatter in the universal stability functions for temperature (Tsvang et al. 1998). Examples of near-neutral wind profiles from the four wind directions are illustrated in figure 4, supporting the $\log$ wind profile assumption.

Table 2. Average and standard deviations of $z_{0}$ and $d_{0}$ estimated from the wind profile data. Results for wind directions from the north, south, east and west and all data (global values) are listed.

\begin{tabular}{lcccc}
\hline $\begin{array}{l}\text { Wind direction } \\
\text { (samples) }\end{array}$ & $\begin{array}{c}\text { Average } \\
z_{0}(\mathrm{~cm})\end{array}$ & $\begin{array}{c}\text { Standard deviation } \\
z_{0}(\mathrm{~cm})\end{array}$ & $\begin{array}{c}\text { Average } \\
d_{0}(\mathrm{~cm})\end{array}$ & $\begin{array}{c}\text { Standard deviation } \\
d_{0}(\mathrm{~cm})\end{array}$ \\
\hline North (27) & 7.2 & \pm 2.2 & 127 & \pm 20 \\
South (14) & 10 & \pm 4.6 & 62 & \pm 75 \\
East (30) & 4.9 & \pm 3.8 & 104 & \pm 70 \\
West (141) & 7.2 & \pm 4.3 & 96 & \pm 40 \\
Global (211) & 7.0 & \pm 4.2 & 98 & \pm 48 \\
\hline
\end{tabular}




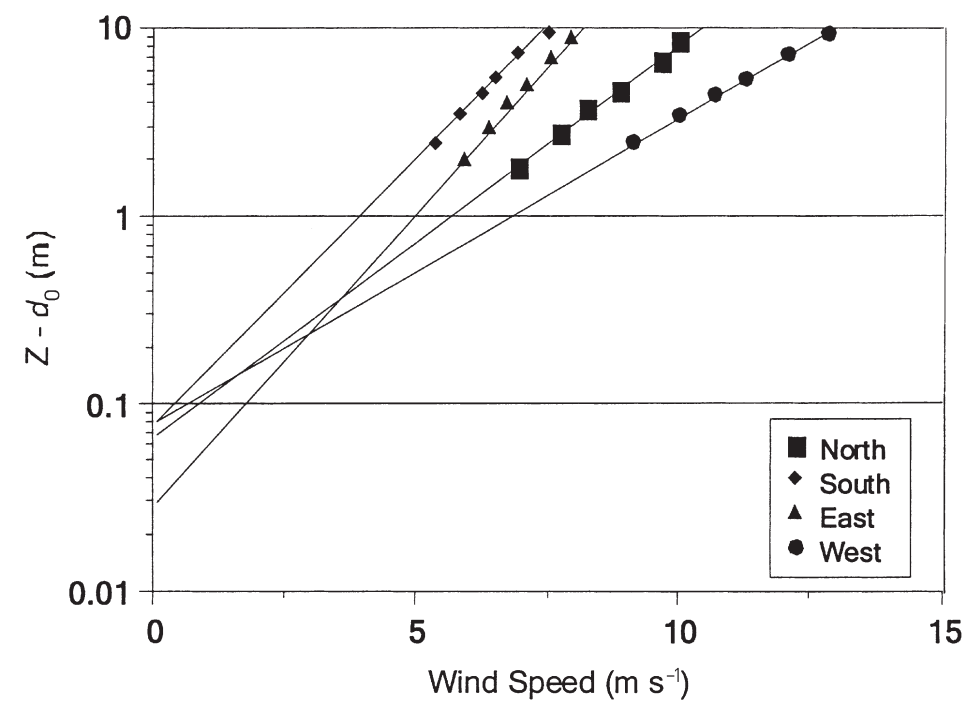

Figure 4. Examples of wind profile data on a semi-log plot for the four wind directions (north, south, east and west). The lines represent 'least-squares-fit' fit to the six levels, with $z-d_{0}$ and the intercept, $z_{0}$, determined by the procedure outlined in Kustas et al. (1989).

In any event, the estimates of $z_{0}$ and $d_{0}$ from the wind data are only used for comparison purposes with the indirect methods using the laser altimeter data. They cannot be used to validate or calibrate model predictions as performed by Hiyama et al. (1996). It is also worth noting that the 100-m engineering survey cross section through the coppice dunes yielded an average total dune plus mesquite height of $1.8 \mathrm{~m}$. Thus taking the $H \approx 1.5 \mathrm{~m}$ (average of laser and engineering survey) yields $z_{0} / H \approx 0.05$ and $d_{0} / H \approx 0.65$, both ratios falling within observed ranges (Brutsaert 1982).

The effective aerodynamic roughness for three laser transects was computed using equation (5) (Kustas and Brutsaert 1986), equation (10) (Grant and Mason 1990), and equation (11) (Mason 1985). Mason (1985) suggested a parameterization of the roughness based on average slope. For transect $N S_{S D}$, the average slope is less than 0.2 , suggesting the use of equation (9). Average $z_{0}$ for Mason (1985) is based on equation (9) for laser transect $N S_{S D}$ in the small dune area and equation (10) for laser transects $N S_{L D}$ and $E W_{L D}$.

The average effective aerodynamic roughness $z_{0}=4.3 \mathrm{~cm}$ (table 3 ) estimated from all three methods with the laser data is within the range of the effective aerodynamic roughness estimated from the meteorological tower data measured at the same site (i.e. $z_{0}=7 \pm 4 \mathrm{~cm}$; see table 2). The method of Kustas and Brutsaert (1986) gave a lower estimate of $z_{0}$ for the north-south laser transect over the smaller dunes $\left(N S_{S D}\right)$. Since in their approach the contribution of the surface shear stress is not considered, this would result in a lower estimate of the effective aerodynamic roughness for the $N S_{S D}$ transect where surface drag would be more important.

The displacement heights (table 3 ) were estimated using equation (12) and yielded results using the laser data which were generally smaller than $d_{0}$ from the wind profile. However, equation (12) is directly proportional to $H$; thus a bias in the value of $H$ from the laser data could significantly affect the estimate of $d_{0}$. Hence if 
Table 3. Summary of estimates for effective aerodynamic roughness $z_{0}(\mathrm{~cm})$ and displacement height $d_{0}(\mathrm{~cm})$ for three laser transects measured at the USDA-ARS Jornada Experimental Range, New Mexico, USA calculated using different methods and wind profile data.

\begin{tabular}{lrrrr}
\hline & \multicolumn{3}{c}{ Transect } & \\
\cline { 2 - 4 } & $N S_{L D}$ & $E W_{L D}$ & $N S_{S D}$ & Average \\
\hline$z_{0}$ & & & & \\
Kustas and Brutsaert (1986) & 5.7 & 4.5 & 1.8 & 4.0 \\
Grant and Mason (1990) & 5.3 & 4.3 & 2.7 & 4.1 \\
$\quad$ Mason (1985), Grant and Mason (1990) & 5.3 & 4.3 & 4.4 & 4.7 \\
$\quad$ Wind profile & 7.2 & 6.7 & 10 & 7.0 \\
$d_{0}$ & & & & \\
Kutzbach (1961), Raupach et al. (1980) $_{\text {Wind profile }^{1}}$ & 92 & 50 & 69 & 70 \\
\hline
\end{tabular}

${ }^{1}$ Estimated from wind profile data (see table 2). Estimates for $E W_{L D}$ come from averaging east and west wind direction data.

$N S_{L D}=$ North/South Large Dunes.

$E W_{L D}=$ East $/$ West Large Dunes.

$N S_{S D}=$ North/South Small Dunes.

$H \approx 150 \mathrm{~cm}$, then using the average $\lambda$ from table $1(\lambda=0.09)$ equation (12) yields $d_{0}=81 \mathrm{~cm}$ which agrees more closely with the global value of displacement height derived from the wind profiles $\left(d_{0}=98 \pm 48 \mathrm{~cm}\right)$.

\section{Discussion}

A sensitivity analysis has been carried out to evaluate the reliability of the method to calculate surface roughness from laser altimetry using the theory of Grant and Mason (1990) and Mason (1985). The model of Mason (1985) was developed for a complex landscape with large orographic obstacles, neglecting any shadowing effects of adjacent obstacles. As shown, the model can be applied in complex areas consisting of smaller scale obstacles. Raupach (1992) showed that for obstacle densities of $\lambda<0.1$, the shadowing or sheltering effects can be ignored. We calculated densities of $\lambda<0.12$ suggesting that the shadowing might have a marginal effect at least.

Form drag, which is mainly due to the large scale obstacles, makes a greater contribution to the effective aerodynamic roughness than shear stress which is due to small scale obstacles. When applying a local roughness of $z_{01}=1 \mathrm{~cm}$ approximately $80 \%$ of the stress is due to the form drag caused by large scale obstacles consisting of the dunes, while surface (shear) stress due to grasses, forbs, and small bushes only contribute $20 \%$. The contribution of form drag is sensitive to local roughness and may vary between $50 \%$ for $z_{01}=5 \mathrm{~cm}$ and $90 \%$ for $z_{01}=0.5 \mathrm{~cm}$.

The choice of the filter used with the laser data is important as the obstacle density $\lambda$, and consequently the effective aerodynamic roughness $\left(z_{0}\right)$ is sensitive to filter size. The applied method to determine the filter size for the laser data, assumes that any overestimation due to noise is compensated by a similar underestimation due to averaging. Without applying a moving average to the laser data, $z_{0}$ is equal to $6.4 \mathrm{~cm}$. This effect is mainly due to the roughness of laser transect $\left(N S_{S D}\right)$ where obstacles are small and density is not important.

Although there is no exact method to obtain the mean local roughness $\left(z_{01}\right)$ it is 
assumed that it is equal to the undisturbed roughness where the effect of form drag is minimum. For the test area, approximately $10-20 \%$ of the area is occupied by grasses resulting in a mean roughness of $\sim 1.0 \mathrm{~cm}$. In the case of a minimum value of $z_{01}=0.5 \mathrm{~cm}, z_{0}=3.8 \mathrm{~cm}$, while for a maximum value $z_{01}=5 \mathrm{~cm}, z_{0}=7.8 \mathrm{~cm}$.

Estimates of aerodynamic roughness are also sensitive to the choice of drag coefficient $\left(C_{d}\right)$. Based on literature a value of $C_{d}=0.3$ (Grant and Mason 1990) has been used. However, it is plausible that for the current area with dunes and vegetation on top, a higher value of $C_{d}$ is more appropriate. An increase in $C_{d}$ from 0.3 to 0.4 (Menenti and Ritchie 1994) would increase $z_{0}$ from 4.7 to $5.5 \mathrm{~cm}$ while an increase in $C_{d}$ from 0.3 to 0.5 (Hiyama et al. 1996) would increase $z_{0}$ from 4.7 to $6.2 \mathrm{~cm}$, which is in closer agreement with the $z_{0}$ computed from the wind profile data.

Finally, a bias in the laser estimated $H$ will also have an effect on the estimated $z_{0}$. The sensitivity to this bias was evaluated for equations (5) and (10) using average surface features from table 1 . With equation (5), and having $H=1 \mathrm{~m}$ and $1.5 \mathrm{~m}$, the $z_{0}$ value changes from $3.4 \mathrm{~cm}$ to $6.0 \mathrm{~cm}$, respectively. With equation (10) the change in $H$ from 1 to $1.5 \mathrm{~m}$ does not have as a dramatic impact on the $z_{0}$ value, increasing from $3.8 \mathrm{~cm}$ to $5.1 \mathrm{~cm}$, respectively.

\section{Conclusion}

A method is presented to derive effective aerodynamic roughness of a complex coppice dune area using high resolution laser altimeter measurements of land surface roughness. This study is based on the theories of Lettau (1969), modified by Kustas and Brutsaert (1986), Mason (1985) and Grant and Mason (1990) to calculate effective aerodynamic roughness from simple surface features.

Results show that estimations of $z_{0}$ and $d_{0}$ of a complex terrain consisting of coppice dunes with bare interdunal areas is plausible using simple terrain features computed from high resolution laser altimeter data. The estimation of $z_{0}$ from Kustas and Brutsaert (1986) gives lower values than $z_{0}$ estimates using Grant and Mason (1990) for the transect containing small dunes where shear stress due to smaller scale roughness elements would be more important (see table 3). Overall, the different model estimates of $z_{0}$ are in agreement, and tend to be lower than values determined using wind profile data. Similarly, the model computed $d_{0}$ is less than the $d_{0}$ derived from the wind profile data. However, the model-derived values fall within the range of uncertainty in $z_{0}$ and $d_{0}$ estimates using the wind profile technique (see table 3 ).

A sensitivity analysis of the models to compute $z_{0}$ indicated the models requiring $C_{d}$ are sensitive to its assumed value, which unfortunately cannot be determined from observed surface features. The range in the value of $C_{d}$ from the literature (i.e. from 0.3 to 0.5 ) can change the $z_{0}$ value for this site by $30 \%$. Any bias in $H$ can also strongly influence model-derived $z_{0}$. In the example used in the present study, a change in $H$ from 100 to $150 \mathrm{~cm}$ caused a $75 \%$ increase in $z_{0}$ using equation (5) and a $35 \%$ increase using equation (10) which is comparable to the increase in $C_{d}$ from 0.3 to 0.5 . The availability of high resolution height data of the land surface commensurate with more reliable roughness values obtained from micrometeorological measurements of wind and surface shear stress would make it possible to evaluate some of the model parameters difficult to determine with the present data set.

\section{Acknowledgments}

The first author is supported by the Dutch Remote Sensing Board (BCRS) Grant Nr. 4.2/AP-03. The authors express appreciation to the USDA-ARS Integrated 
Farming and Natural Resources Research Unit, Subtropical Agricultural Research Laboratory, Weslaco, TX for the use of their Aerocommander as the platform for flying the instrument. Special appreciation goes to M. R. Davis, pilot, USDA-ARS, Weslaco, TX, who flew the Aerocommander. Sincere appreciation is due to the staffs of the USDA-ARS Jornada Experimental Range, Las Cruces, NM, USDA-ARS Hydrology and Remote Sensing Laboratory, Beltsville, MD, and the USDA-ARS Soil Tilth Laboratory, Ames, IA who provided logistical and ground support before, during, and after the airborne campaigns.

\section{References}

ARYA, S. P. S., 1975, A drag partition theory for determining the large-scale roughness parameter and wind stress on Arctic pack ice. Journal of Geophysical Research, 80, $3447-3454$.

Brutsaert, W., 1982, Evaporation into the Atmosphere (Holland: D. Reidel).

Covey, W., 1963, A method for the calculation of logarithmic wind profile parameters and their standard errors. In The Energy at the Surface, Part II, Report no. 72, USDAARS, Washington, DC, pp. 28-33.

Gibbens, R. P., Tromble, J. M., Hennessey, J. T., and Cardenas, M., 1983, Soil movement in mesquite dunelands and former grasslands of southern New Mexico from 1933 to 1980. Journal of Range Management, 36, 145-148.

Grant, A. L. M., and Mason, P. J., 1990, Observations of boundary-layer structure over complex terrain. Quarterly Journal of the Royal Meteorological Society, 116, 159-186.

Grover, J. R., and Musick, H. B., 1990, Shrubland encroachment in southern New Mexico, USA: and analysis of desertification process in the American Southwest. Climate Change, 17, 305-330.

Havstad, K. M., Kustas, W. P., Rango, A., Ritchie, J. C., and Schmugge, T. J., 2000, Jornada Experimental Range: A unique arid land location for experiments to validate satellite systems and to understand effects of climate change. Remote Sensing of Environment, 74, 13-25.

Hignett, P., and Hopwood, W. P., 1994, Estimates of effective surface roughness over complex terrain. Boundary Layer Meteorology, 68, 51-73.

Hiyama, T., Sugita, M., and Kotoda, K., 1996, Regional roughness parameters and momentum fluxes over a complex area. Journal of Applied Meteorology, 35, 2179-2185.

Kaimal, J. C., and Finnigan, J. J., 1994, Atmospheric Boundary Layer Flows; their Structure and Measurement (Oxford: Oxford University Press).

Kustas, W. P., and Brutsaert, W., 1986, Wind profile constants in a neutral atmospheric boundary layer over complex terrain. Boundary Layer Meteorology, 34, 35-54.

Kustas, W. P., Choudhury, B. J., Kunkel, K. E., and Gay, L. W., 1989, Estimate of the aerodynamic roughness parameters over an incomplete canopy cover of cotton. Agricultural and Forest Meteorology, 46, 91-105.

Kustas, W. P., Prueger, J. H., Hipps, L. E., Ramalingam, K., Hatfield, J. L., Schmugge, T. J., Rango, A., Ritchie, J. C., and Havstad, K. M., 1998, Application of Monin-Obukhov similarity over a mesquite dune site in the Jornada experimental range. In AMS Proceedings $23^{\text {rd }}$ Conference on Agricultural Forest Meteorology, American Meteorological Society, Albuquerque, NM, USA, pp. 216-219.

Kutzbach, J., 1961, Investigations of the modification of wind profiles by artificially controlled surface roughness. Annual Report, Department of Meteorology, University of Wisconsin-Madison.

Lettau, H., 1969, Note on aerodynamic roughness parameter estimation on the basis of roughness-element description. Journal of Applied Meteorology, 8, 828-832.

Mason, P. J., 1985, On the parameterization of orographic drag. In Physical Parameterization for Numerical Models of the Atmosphere, E.C.M.W.F., Reading, Seminar, 9-13 September 1985, pp. 139-167.

Menenti, M., and Ritchie, J. C., 1994, Estimation of effective aerodynamic roughness of Walnut Gulch watershed with laser altimeter data. Water Resources Research, 30, 1329-1337. 
RAUPACH, M. R., 1992, Drag and drag partition on rough surfaces. Boundary Layer Meteorology, 60, 375-395.

Raupach, M. R., Thom, A. S., and Edwards, I., 1980, A wind-tunnel study of turbulent flow close to regularly arrayed rough surfaces. Boundary Layer Meteorology, 18, 373-397.

Ritchie, J. C., 1995, Airborne laser measurements of landscape topography. Remote Sensing of Environment, 53, 91-96.

Robinson, S. M., 1962, Computing wind profile parameters. Journal of Atmospheric Science, 19, 189-190.

Schmid, H. P., 1994, Source areas for scalars and scalar fluxes. Boundary Layer Meteorology, 67, 293-318.

Schuepr, P. H., Leclerc, M. Y., Macpherson, J. L., and Desjardins, R. L., 1990, Footprint prediction of scalar fluxes from analytical solutions of the diffusion equation. Boundary Layer Meteorology, 50, 355-373.

Stearns, C. R., 1970, Determining surface roughness and displacement height. Boundary Layer Meteorology, 1, 102-111.

Taylor, P. A., Sykes, R. I., and Mason, P. J., 1989, On the parameterization of drag over small scale topography in neutrally stratified boundary layer flow. Boundary Layer Meteorology, 48, 409-422.

Tsvang, L. R., Kukharts, V. P., and Perepelkin, V. G., 1998, Atmospheric turbulence characteristics over a temperature-inhomogeneous land surface. Part II: the effect of small-scale inhomogeneities of surface temperature on some characteristics of the atmospheric surface layer. Boundary Layer Meteorology, 8, 103-124.

WIERINGA, J., 1993, Representative roughness parameters for homogeneous terrain. Boundary Layer Meteorology, 63, 323-364.

Wooding, R. A., Bradley, E. F., and Marshall, J. K., 1973, Drag due to regular arrays of roughness elements of varying geometry. Boundary Layer Meteorology, 5, 285-308. 